\title{
How do police officers talk about their encounters with 'the public'? Group interaction, procedural justice, and officer constructions of policing identities
}

\begin{abstract}
Despite widespread empirical support for Procedural Justice Theory, understanding of the role of police psychology in shaping encounters with 'citizens' is relatively opaque. This paper seeks to address this gap in the literature by exploring how officers talk about themselves, their colleagues and deploy social categories to understand their interactions with 'the public'. The qualitative thematic analysis draws upon 22 semi-structured interviews conducted with officers in various roles and teams within a large metropolitan police force in England. Our thematic analysis demonstrates the centrality of procedural fairness in officer talk (in terms of internal relations with colleagues and external relations with 'the public'). Interviewees described complex internalised theories of social relations, differentially positioning themselves in relation to other colleagues and multiple 'publics' often depicted along socioeconomic and geographical lines. Officers described their interactions with 'the public' in sequential and historical terms with complex and changing (often intergroup) power dynamics. Implications of the analysis for understanding the role of social identity processes among police officers and how this underlying conceptualisation might shape police- 'citizen' encounters are discussed.
\end{abstract}

Keywords: Procedural Justice; Police Psychology; Social identity; Police - public interactions; Selfcategorisation

Word count: 8,905

\section{Introduction}

Developed in the late 1980s and early 1990s, Procedural Justice Theory (PJT: Lind and Tyler, 1988; Tyler, 1990) has evolved to become a popular theoretical perspective both in criminological research and policing, helping to both explain and shape encounters between police officers and 'the public'. As O’Brien, Tyler and Meares (2019) outline, PJT is often seen as an individual-level model of authority. Accordingly, PJT's underlying theoretical account is often that of a dyad between a police officer and a 'citizen' (Radburn et al., 2018). Indeed, there is an extensive body of evidence to support its main proposition that such interpersonal interactions between 'the police' and 'citizens' can be central to public compliance and cooperation with officers (Sunshine and Tyler, 2003a). In particular, research suggests that if a 'citizen' perceives that a police officer is treating them fairly then that citizen is more likely to perceive the police as a legitimate authority 
(Tyler, 1990). In turn, once a citizen confers legitimacy on a police officer then they will be more likely obey the instructions of the officer out of a sense of 'moral duty' (Jackson et al., 2012).

Yet despite such widespread empirical support and extensive uptake of the concept operationally by police forces (MacQueen and Bradford, 2015), there is increasing recognition of a need to build upon the theory's current scope and explanatory power (Bottoms and Tankebe, 2012; Harkin, 2015; Jackson \& Posch, 2020; Radburn et al., 2018). In part, these calls are motivated by the fact that there are important questions about the extent to which PJT can deal adequately with the complexities of day to day encounters between police and the public across a range of different, often challenging, contexts (Worden and McLean, 2017). Among others, Bottoms and Tankebe (2012) have argued that it is important to understand and explore the dynamics of how legitimacy and fairness are achieved within the interactions between police as 'power-holders' and those who are being policed. Additionally, O’Brien, Tyler and Meares (2019) have sought to advance the theory by proposing an intergroup model of authority community relations. Moreover, Jackson and Posch (2020) explore the potential role of motivated cognition, identity and power in shaping how interactions with police officers are understood. In effect, the argument is that according to PJT, actors in police-citizen encounters are involved in a process and do not enter their interaction 'theory free'. As Worden and McLean (2017: 48) put it “we can safely assume that the typical adult is not a blank slate on which direct experience with legal actors leave their mark". Furthermore, Urbanska et al. (2019) and Radburn and Stott (2019) have suggested there is a pressing need to understand the role of historically situated group-level dynamics embedded within such interactions between the police and the 'public'. This paper seeks to contribute to these conceptual developments by exploring how police officers talk about themselves and their interactions with the public.

\section{Theorising and researching social identity in the context of police-'public' interactions}

PJT research has historically drawn on Social Identity Theory (SIT: Tajfel and Turner, 1979) to conceptualise the group-level psychological dimensions of police-citizen encounters (Lind and Tyler, 1988; Tyler and Blader, 2003). However, despite this legacy, it is important to note some salient differences in precisely how social identity is theorised in PJT research compared to contemporary Social Psychology ${ }^{1}$. Specifically, within PJT research, the police and 'the public' are often conceptualised as belonging to the same social group (usually defined in terms of either community or national identity). Accordingly, by virtue of their position as powerful and 'morally

\footnotetext{
${ }^{1}$ In contemporary social psychology it is now common to refer to the 'social identity approach', which includes both Social Identity and Self-Categorisation Theory as well as their application to various issues such as the behaviour of crowds (i.e., the Social Identity Model of crowd behaviour and Elaborated Social Identity Model of crowd behaviour).
} 
prototypical group leaders' (Sunshine and Tyler, 2003b), police behaviour in their interactions with 'citizens' indicates to those 'citizens' their relative standing within these important psychological categories. Thus, procedurally fair police treatment indicates inclusion and high standing (e.g., "I am a valued member of my community"), whereas procedurally unfair police treatment indicates exclusion and low standing (e.g., "I am not a valued member of my community").

In contrast to the dominant PJT approach with its focus on intragroup relations, SIT is fundamentally a theory of intergroup relations and recognises that society is comprised of multiple social groups that differ in terms of status and power. Its sister Self Categorisation Theory (SCT), focuses on the functioning of the self. It delineates the processes through which people come to develop a sense of psychological belonging to these groups and how these social identities come to be salient and drive, and are driven by, group processes and intergroup relationships (Turner et al., 1987, 1994). Thus, central to social identity are complex social cognitive processes of social categorisation, comparison and differentiation. These are conceptualised as the basis through which individuals psychologically position themselves within and understand how to act collectively within any given social context. In this way, identity is fundamentally social, comparative and contextual and that you therefore cannot possess a sense of self without a contextually relevant theory of 'the other'. As Tajfel (1981: 323, original emphasis) put it, "we are what we are because they are not what we are". This is important since it suggests, in contrast to PJT, that police officers and 'citizens' may not view themselves as members of the same social categories (e.g., 'community', national identity) within a given situation. For instance, in the context of a protest a 'citizen' may define themselves and others in contrast to the police officers present (e.g., 'us' climate change activists vs. 'them' police). Additionally, police officers may also psychologically view themselves as a distinct social group, differentiating 'us' police as separate from those they are policing (c.f., Herbert, 2006).

What this suggests is that social identity is more than emotional attachment and strength of belonging to a social group - it is instead a complex, subjective and often shared theory of social (intergroup) relations. It is our contention that the bulk of associated and subsequent PJT research tends to assume the former conceptualisation of social identity and as such is currently limited in its capacity to adequately explain these group-level psychological dynamics of police interactions with the public. Moreover, the PJT work that has focused upon identity processes tends to do so among those being policed (e.g. Bradford, 2014; Bradford et al., 2014). Thus, what remains opaque is the nature of social identity processes among police officers and how these might affect and 
inform the group-level dynamics of their 'dialogic' interactions with the public. Furthermore, the PJT work on police identity that does exist currently focuses largely on the issue of 'self-legitimacy' and officers' sense and levels of identification with their own organisation in order to understand the implications this might have for officers' subsequent encounters. For example, Bradford and Quinton (2014: 1045) suggest that organisational identification can be positively related to officers' commitment to democratic policing ideals (e.g., support for procedurally just policing methods, suspects' rights). While these issues are important, as Bradford and Quinton (2014: 1039) acknowledge, the idea that the psychological dynamics of police-citizen encounters can be adequately understood merely in terms of a singular monolithic organisational identity is problematic because "police officers are likely to have multiple, cross-cutting and possibly contradictory identities and beliefs". Thus, what remains underexplored is the potential role of these more complex social identity processes among police officers and how these define and give meaning to their often highly locally contextualised and dynamic interactions with 'citizens' (Charman, 2019).

Nonetheless, the complexity of police identity and the cultural practices of officers has been long recognised (e.g., Banton, 1964; Skolnick, 1966; Westley, 1970). Within this body of work, it is argued that there is a typology of characteristics that constitute an orthodoxy of police occupational subculture (e.g., masculinity, extreme 'cynicism', pragmatism; see Reiner, 2010). More recent debates around police culture have centred on the extent to which these 'classical' conceptualisations are still relevant given the huge organisational, political and social changes experienced since these initial ethnographies were undertaken (e.g., Charman, 2018). Loftus (2010: 1) has argued that 'police identity' and cultural practices in the UK have indeed shown remarkable endurance. Whereas Sklansky (2007: 21) maintains that police officers have demonstrated a level of psychological agency in redefining their sense of identity and shared cultural practices within specific (social historical) contexts. While both positions may ultimately be true this literature is important here because it highlights a complexity to police identity that reinforces the call by Bradford and Quinton (2014) to transcend global notions of mere 'organisational identification' and for PJT research to recognise and explore the multifaceted (and intergroup) nature of police identity.

\section{Current study}

This paper seeks to address the above limitations by providing an empirical exploration of police talk about themselves and their routine interactions with the public. Our central aim is to explore empirically how officers talk about themselves and others and whether or not procedural fairness 
and group-level dynamics are a feature of how officers describe their normal working practices. On this basis, we then aim to analyse the extent to which dominant assumptions within the PJT literature are adequate in capturing the broad parameters of the themes we identify. Following the work of Loftus (2010), we distinguish between officer talk and officer behaviour and focus here upon the former, considering how officers describe themselves and their work rather than observing that work in practice. We therefore analyse officer talk as a means of exploring the dynamics perceived by officers in their interactions with the public, whilst acknowledging the important limitations of an approach not focused on actual police behaviour (Waddington, 1999).

As such, the paper presents an analysis of interview data with police officers working across a range of roles and teams (e.g., response, neighbourhood) within one of the largest metropolitan police forces in the United Kingdom ${ }^{2}$. Rather than treating this talk as a reflection of the 'reality' of policing, the data are considered in its own right inductively comparing the accounts of a sample of officers occupying different roles and ranks but all of whom are involved in 'front line' policing. Through this approach, we sought to build an analysis of the kinds of meaning that might guide police actions, drawing conclusions about how the data may help understand the potential complexity of the interactive processes at work in encounters between police and the public.

The broad research question driving the paper is: how do police officers talk about and 'make sense' of their varied interactions with the people they police? Related to this are a set of specific issues regarding the construction of police identity and categorisation: how do police officers talk about themselves, how do they talk about 'the other', and how do those notions of self and other influence how officers talk about their policing roles and encounters with the public?

\section{Method}

After gaining informed written consent of the Chief Officer team, the duty inspector, and police officer participants, a total of 22 semi-structured interviews were conducted between March 2019 and May 2019. Our sample consisted of 9 female and 13 male officers; 6 worked within neighbourhood policing teams, 10 in response policing, 4 in criminal investigation, 1 in integrated offender management and 1 in police custody. Of those, 1 ranked as a chief inspector, 2 as inspectors, 3 as sergeants, 14 as constables and 2 community support officers. The officers worked

\footnotetext{
2 This paper is the first reported component of a wider ethnographic research project exploring the role of social identity and legitimacy within PJT. For more information see: https://gtr.ukri.org/projects?ref=ES\%2FR011397\%2F1
} 
in varied geographical areas of the force. Interviews were conducted in the police station from which the officer was working on that shift and lasted approximately 60 minutes. Participants were an opportunity sample, interviewed on the basis of their availability and willingness to partake during the data collection period. In line with the aims and scope of the analysis, the interview questions were partly exploratory but also theoretically driven, reflecting an interest in officers' general understanding of their role, identity and actions. Participants were asked about: their policing role, what motivates them to do their job, how they thought about themselves, perceptions of police legitimacy, and their expectations and perceptions of the public.

\section{Analytic procedure}

The analytical approach employed a form of thematic analysis based on Glaser and Strauss (2017). First, the authors listened independently to each of the audio-recorded interviews and took notes on what they judged to be meaningful episodes. Second, guided by theory, team members independently extracted and transcribed quotes from the interviews that exemplified what they judged to be recurring or theoretically relevant issues. The research team converged over a period of several weeks to discuss the episodes identified. During these analysis sessions a broad thematic structure of the data was developed and those were reviewed once all interviews had been discussed, allowing the episodes to be organised into a single coherent thematic structure. Team members then re-listened to the audio recordings to ensure that the thematic structure had a good 'fit' with the interview data (Henwood and Pigeon, 2003). Where any anomalies were identified the broader themes were nuanced to capture and more fully describe the underlying data. Finally, quotes that were judged to best represent the final themes were chosen and are presented in the following analysis.

This approach of providing single exemplars is necessary for reasons of space and brevity. Perhaps more substantially this approach relates to the philosophy of science underpinning our work. Providing multiple examples or implied quantitative measures, of the ubiquity of particular themes refers to the generalisability, reliability or consistency of these views across the sample. We do not wish to convey these assumptions about our methodology. Indeed, as Smith and McGannon (2018: 112) have argued: "seeking reliability becomes nonsensical because a qualitative researcher seeking rich and personally meaningful information from people in interviews does not ask the same questions, in precisely the same order, with the same non-verbal expressions or emotional tone, in repeated social contexts and situations, with no change in their knowledge based on previous interviews, and so on". Accordingly, unlike quantitative content analyses, our exploration of officer talk did not seek to determine the numerical frequency 
of the theoretically informed patterns that we have presented in the analysis section. Rather we have sought to be transparent about the inherent benefits and weaknesses of our methodology and we leave it to the reader to judge, on the basis of their own expertise, whether our data and theoretical analysis provide a meaningful contribution to the literature.

\section{Analysis}

The centrality of procedural fairness

We begin by highlighting the central emphasis that officers placed on notions of fairness and justice within their daily work and interactions with members of the public. Throughout the interviews officers highlighted key aspects of 'procedural justice' as it is currently conceptualised in theory, including the need to treat people with dignity and respect, the need to emphasise the 'trustworthiness' of police motives and to give the public 'voice' by including them in their decisions of 'how' to police. However, for some this was emphasised through the potential negative ramifications of public perceptions of unfairness, important because it could disempower police and inhibit the realisation of strategic goals. For instance, one officer described a failed attempt to deal with high crime rates through installing CCTV cameras into an area populated by a large BAME community.

'There was a massive distrust. So immediately, it was like you're just spying on us, you've just branded us all as terrorists. There was going to be a reason why all the cameras were put up and that may have been one of the reasons but because it's not sold to the public you struggle to claw it back, they took the cameras down, so they gave into the community." (Male response officer, 0J3T)

Other officers also depicted 'voice' as a means to prevent such notions of police unfairness, and the subsequent resistance to police action it created, from developing. For example, when planning to use a drone to undertake surveillance one officer described how this was likely to be seen as illegitimate by the local population and how a community Independent Advisory Group (IAG) ${ }^{3}$ was utilised as a means through which such perceptions of unfairness could be averted.

"And they met, you know, as a collective. I think they went away, came back with some questions: Why are you using a drone? What are you going to do with it? How is it going to reduce crime in the area? We were able to satisfy those concerns through using key people within the community. I think. from working in

\footnotetext{
${ }^{3}$ An IAG can be defined as a voluntary, self-governing group that represent a community within a geographical area, providing independent advice to the police concerning issues within that community.
} 
this area anyway the community appreciate transparency, we're not hiding the fact that we are going to use it, you know so we're not, there's no bidden agenda." (Male neighbourhood officer, 1N6H)

Thus, our interviewees often talked about procedurally fair policing in instrumental and grouplevel terms, that is, as a means of preventing adverse community-wide responses and to avoid public complaints. In other words, officer talk about 'procedural justice' and the importance of the four key tenets (dignity and respect, trustworthy motives, neutrality and voice) appeared to be related to an accountability dynamic whereby 'fair' policing was described as valuable as a means of avoiding conflict and confrontation.

Alongside this emphasis on 'external' procedural fairness within officers' talk they also described the importance of procedural fairness internally to their own organisation, in terms of their interactions with and treatment by supervisors, senior leaders and public bodies to which they were accountable. For example, trust from immediate supervisors was described by one officer as integral to his view of the quality of their occupational relationship.

'T've had some bad sergeants where they micromanage and if you're being put into a role like a police officer there's got to be a level of trust, clearly, because you make a lot of important decisions, and if they don't trust you... you just feel like what's the point in me doing all of this if you're not going to trust me as a police officer." (Male response officer, OP6H, 19:30)

Thus, the salience and need for organisational justice and trust within their organisation was a key feature of officer talk. Yet interviewees frequently described an absence of trust with senior management and 'the job', in contrast to more positive relations within their immediate teams. This again, like descriptions of external procedural justice above, related to an accountability dynamic and specifically the extent to which officers felt they would be supported in light of public complaints about their conduct.

I wouldn't sit here and say I'm 100\% confident they would back me if something bad, if something horrible went wrong, as in the job itself, colleagues and supervision would yeah, but the job in itself... if you're doing your job and something happens, that's where I think a lot of people don't feel backed." (Male response officer, 0M1D) 
In summary, with this section we highlight how core concepts of procedural fairness were a consistent theme within officer talk in at least three ways: 1) by describing issues experienced in their relationships with community groups; 2) in building trust, allowing opportunities for voice and acting in a neutral/transparent manner; and, 3) in terms of their relationships within their own organisation.

\section{Self, other and context}

Despite this initial endorsement of concepts central to PJT our data also begins to expose how officers' talk constructs a complexity to their interactions that fits less easily with some interpretations of current theory. While police officers talk drew heavily on concepts of a singular 'police family' they equally described how they populated multiple and very different policing roles, such as neighbourhood and response policing or offender management. Moreover, these diverse roles were characterised as having distinctive normative and moral characteristics that had implications for, and sometimes challenged, what it means to be a police officer. As one response officer recalled when discussing the introduction of neighbourhood policing, there was an adverse reaction among his colleagues because it was a role that was seen to be counter normative to dominant masculine ideas about what a police officer should be.

"When neighbourbood policing came in, it was very much nobody wanted to go and do that because it was that's 'soft, fluffy, pink' side of policing that didn't really appeal to people." (Male response officer, $0 \mathrm{~J} 3 \mathrm{~T})$

In contrast, a neighbourhood officer described response work as reactive, short term and chaotic. As such her erstwhile response colleagues were unable to utilise the more considered forms of policing that were described as the dominant approach among the neighbourhood teams.

'I think some response officers where they have to go job, to job, to job, to job, they don't have the time to apply calm, rational conversation... we are far more likely to want to sit down and have a chat with somebody." (Female neighbourhood officer, 1M3H)

Such accounts of contrasting roles and identities expose how officers talk challenges the idea of some universal singular notion of police identity. Instead, as the above extracts imply, our data is consistent with the idea that there are two distinct or different 'styles' or modes of policing which 
are heavily influenced and structured by gender, summed up neatly by a female response officer in our sample.

"You get two types of people in this job. You get the people who want to go chasing everyone, cars, drugs, you know, getting hands on. And you get people who, and I will say it, it is generally the women, who have got a more nurturing feel for the job, they'll go to a job, much rather sit down with somebody, spend a bit of time with them, talking through..." (Female response officer, 0E2A)

Officers' talk about themselves drew on comparisons not just in relation to other colleagues but also with the public. Such talk reflected the much higher levels of policing demand, and therefore contact with, people in more deprived and often more ethnically mixed neighbourhoods within their jurisdiction. In other words, their encounters with 'the public' were described as locally contextualised and as far more frequent and problematic in areas of economic deprivation relative to more affluent neighbourhoods. Such comparisons were particularly relevant because some officers described people in these areas as often very different from and alien to the stable middleclass backgrounds from which they themselves originated.

"I think one of the biggest issues that we face as a police force is the majority of us will have come from quite stable, quote unquote normal, backgrounds. Obviously not everyone, but for me, I come from a very lucky, affluent, middle class background in Xshire, and my understanding of these kind and their lives, I would never be able to, in a million years, understand what they've gone through in their short lives because I've never had to go through that." (Female neighbourhood officer, 1M3H)

Or as one CID officer put it about her prior history as a PCSO:

It [the PCSO role] gave me that grounding of how to talk to somebody who's from, not from an upbringing that I had, somebody who has got nothing. (Female criminal investigation officer, 1C2W)

Moreover, when encountering people in these communities some officers, far from being able to command a 'procedurally fair' interpersonal encounter, described disempowerment and intergroup rather than dyadic relationships. As one officer described, when travelling into one economically deprived neighbourhood, they would carry with them expectations of a high risk of immediate collective hostility and threat. 
"The majority of the areas we cover... a lot of them are quite deprived run-down areas and without doubt when you go through there or you go to a job in there I would say 90\%, 95\% of the time then no you're not supported [by the local community] at all. You're without doubt the enemy. It doesn't matter, they don't even know what's gone on, you're the enemy straight away." (Male response officer, 0M1D)

This was not only evident in how officers talked about 'others' in the abstract but also in their accounts of actual interactions having received a call for service. For example, one response officer recounted an ostensibly 'low key' incident - a minor car crash - which quickly developed into a group-level interaction between the police officers who responded to the call and community members who mobilised to confront the police.

Two cars and there was nothing sort of untoward about it, it wasn't a police pursuit notbing like that but then suddenly it was up in [place name] and then before you know it you've got like 50, 60 people on the street. The officers that tried to arrest the guy who had left the car and gone into a house or something and then everybody's blaming the police basically, 'why are you arresting bim, he hasn't done anything wrong' and it's that kind of mindset that's like on a daily basis. (Male response officer, 01MD)

In sharp contrast, there was a single officer in our sample that described his own identity as rather uniquely more closely aligned with those communities. In his account he draws upon his own BAME identity to differentiate himself as distinct from his police colleagues and as such more capable of engaging positively with those within the economically deprived neighbourhoods.

"I grew up in an area where gangs exist, I grew up in an area where knife crime... people get stabbed and shot where I grew up, you know, quite a lot, so in all fairness, when someone's talking to me about something and telling me about stuff, I can probably relate to it a bit more than probably most people on this team because of the environment I've had to grow up around... sometimes they will speak to me a different way to how they might speak to one of my white colleagues." (Male neighbourhood officer, 1N6H)

An account that starkly contrasts with officer descriptions of 'citizen' behaviour from more affluent areas of that same jurisdiction.

You go to more affluent areas of [city] and you knock on somebody's door and they can't do enough for you, 'please come back', 'please pop in for a cup of tea', 'ifyou need anything', 'we love the police'. (Female detective, $1 \mathrm{C} 2 \mathrm{~W}$ ) 


\section{Complexity and power}

As we have already seen, officers talk about themselves drew upon themes revolving around a series of group-level comparisons with different and locally contextualised 'publics' or 'communities'. Additionally, far from being seen as isolated or discrete one-off encounters, the interviewees described interactions with 'citizens' as sequential and historical. On the one hand, officers discussed how they would take their own experiences of prior encounters into future ones in ways that affected their judgements and interactions.

'For me mentally, it was, how can I go and deal with such a, what I felt was a meaningless job, 'you've had an argument with your husband?', well hang on, I've just been with someone whose husband just nearly died in front of her. What? I just really felt that I couldn't deal with it because I just felt that I was gonna lose my mind. You're complaining about notbing.” (Female response officer, $0 \mathrm{~K} 4 \mathrm{H}$ )

On the other, officer interactions with some individuals were described as having occurred on multiple prior occasions.

"You turn up for the seventh time to somebody who has called you because they've been attacked, and you know the reason they've been attacked is because they're a registered sex offender or they're a drug dealer and if you spoke to some people they would say well, deserve it, they were asking for it weren't they." (Female neighbourhood officer, 1M3H)

Moreover, officer descriptions of their encounters with 'citizens' portray them as embedded historical encounters with police in general, with group-level consequences that need to be acknowledged and through careful intervention shaped and managed across the longer term.

'People say 'I don't like the police, 10 years ago this officer said this', 'well that was 10 years ago, and I'm not that officer, talk to me', and hopefully me getting on with that particularperson, be'll approach the next police officer or PCSO with a kind of, a bit more open mind and start the process again..." (Male neighbourhood PCSO, 1R5F)

Officers descriptions of their encounters were also not only confined to calls to service but also about their experiences after individuals had been arrested and detained. Accordingly, the interviewees often depicted complex and varied interactions with 'citizens' who were presumed to 
have committed an offence and these encounters often involved a number of other important stakeholders (e.g., fellow officers, solicitors, etc.). For example, when asked about what he liked about interviewing a 'person in custody' (PIC), a male detective in our sample portrayed it as a subtle interplay of dominance and control.

In a suspect interview it's almost a game of cat and mouse, in that you are supposed to be in charge of the interview but as the interview goes on they will try and control it ... it's about the thrill of the chase, and sometimes when you go into suspect interview you know you have got good evidence against that person and it is good to see how they react to that evidence. (Male detective, 1J0B)

Our interviewees also talked of the need to assert control within a context of several actors, such as the PIC's legal representatives.

When you leave the solicitor for consultation with the person in custody, never ask them how long they want, you tell them how long, because you're leading that investigation, you are telling them what they're doing, they are not dictating to you, so that is something that I've always done. I'll say 'T'll give you 15 minutes', and nobody pushes that then. (Female detective, 1C2W)

This was not just in relation to the amount of consultation time that a solicitor receives with their client but was also described as crucial to determining the nature of a suspect's conduct in the interview itself.

....when it comes to dealing with the solicitor, it is a bit of a game, and the solicitor comes into the station knowing that. When I talked about staged disclosure before, solicitors don't like that. They know when it's coming and they turn around and say 'this is the perfect way for you to get a no comment interview, because until I know everything you've got I'm going to tell my client not to say anything'. (Male detective, 1J0B)

Thus, police officers, in their dealings with others, were not described as de facto power holders by our interviewees and indeed they described instances of almost visceral police disempowerment.

"I needed to arrest him... I trusted what he was saying to me, and he said he needed to go inside the house and put the dogs away... and he went in the house, he locked the door and he did one out the back, and obviously, as you can imagine, that didn't go down very well, and I was mortified. I remember speaking to 
his mates who were there, and I was like 'seriously, he's really screwed me over, I trusted him and he's let me down', and I felt let down... And even his mates were like 'we're really sorry miss, I can't believe he's done that, we will try and phone him, we'll try and get him to come in and see you'. Genuinely they were gutted. And even he, afterwards, obviously it all got sorted, but he phoned me and apologised. He was like 'my friends told me that you were gonna get in a lot of trouble and I'm sorry but I didn't want to spend the night in a cell.' He said 'my friends said that you were sad', and I was, I was sad." (Female response officer, $0 \mathrm{~K} 4 \mathrm{H}$ )

In summary, this section has highlighted: 1) the sequential and historical nature of police officer encounters with citizens, 2) that officer experiences of interactions with members of the public are informed by their prior experiences and understandings, 3) that officer descriptions often recognised how members of the public share an historically informed group-level understanding of the police and policing and that this history needed to be acknowledged and managed in the context of their own encounters with 'citizens' and, 4) that there are complex and sometimes subtle changes of power within police-public encounters that often involve other 'actors' (e.g., solicitors).

\section{Discussion}

The core purpose of this paper was to explore how police officers talked about and 'made sense' of themselves and their myriad interactions with citizens. In so doing, the paper focused on how our interviewees talked about their colleagues, 'the public' and their daily interactions with people. To achieve this, we undertook semi-structured interviews with police officers that occupy a variety of frontline roles in order to explore their complex descriptions of 'self' and 'other'.

Our analysis suggested the centrality of 'procedural fairness'. Officers highlighted the importance of acting in 'procedurally just' ways to maintain functional relationships with various community groups (e.g., the salience of police transparency, providing an opportunity for community 'voice' with regards to police decision-making). Yet procedural fairness was often described in instrumental terms in so far as it was delineated as a means to prevent adverse reactions as well as a tool to proactively construct normative compliance. Our interviewees also emphasised through their talk the salience of internal dynamics of 'procedural justice' within their police force. However, our analysis then demonstrated the complexity of police identity talk that transcends fixed and relatively stable notions of a singular police organisation. Instead, our interviewees demonstrated multi-faceted accounts of 'self' and 'other' which could not be easily divorced from their descriptions of the specific social comparative contexts to which they related. Moreover, the 
interviewees talk challenged any assumption that interactions with the 'public' can be adequately understood merely as ahistorical, in that previous encounters with citizens directly informed officers' accounts of subsequent interactions. Finally, our analysis underlined the complex accounts of changing power dynamics within police-'public' interactions that included multiple criminal justice 'actors' such as solicitors. Thus, our study of officers' talk reinforces the idea that police-'public' interactions cannot be adequately conceptualised merely as isolated, decontextualised and interpersonal exchanges between a police officer and a citizen.

Therefore, the analysis presented here concords with Bradford and Quinton's (2014) findings that internal procedural justice matters: that frontline officers valued supervisors who supported them and who sought to build relationships characterised by high levels of trust and autonomy. Moreover, our findings indicated that officers talked about the value of external procedural justice - the extent to which officer actions and decisions are considered fair by members of the public largely in instrumental terms. This often related to accountability concerns (Waddington, 1994) and to what Charman (2017) has termed the 'blue code of self-protection' rather than simple depictions of support for the normative appropriateness of procedurally fair principles of policing.

Our analysis also supports O'Brien et al. (2019) in highlighting the need for PJT theorists to move beyond an individualist model of authority relations and legitimacy dynamics. For example, our interviewees stressed the importance of the police being viewed as 'procedurally fair' but in ways that indicated a cognisance of the 'multiple audiences' (Bottoms and Tankebe, 2012) or communities as a whole to which they need to appeal to and thus gain legitimacy from. Therefore, whilst our work emphasises the importance of understanding the 'other' in addition to the 'self, it also recognises the parallel importance of appreciating the (inter)group and the social element of policing and in particular the myriad social interactions that are inherent to the public role of policing (e.g., with members of the 'public', fellow officers, those working in other parts of the criminal justice system etc.).

Additionally, our work highlighted that present in officers' talk was a strong sense of historical (often intergroup) interactions within particular economic geographies, locations with very different levels of demand on police time. These locations were described as having very different types of 'public' defined in terms of class as well as ethnicity, populated by people who were very similar or different to the officers themselves. Correspondingly, officers described people within those very different communities as viewing the police as 'friend' or 'foe', which has implications 
for the way in which officers might differentially treat and interact with people in these communities. In these ways, the analysis challenges a simple conceptualisation of police-'public' interactions as merely interpersonal in nature and points further toward the utility and necessity of exploring the group-level nature of relations between police officers and 'citizens' and the economic and political geography within which they occur (c.f., Clarke et al., 2007; O’Brien et al., 2019; Radburn et al., 2018; Urbanska et al., 2019).

We also find some support for ideas about the enduring forms of police culture outlined by classical policing ethnographies. For example, police identity was often heavily gendered in our interviewees' talk, with clear examples of machismo (see Miller, 1999; Reiner, 2010) in descriptions of 'what it means to be a police officer'. However, our interviewees were far from uniform in describing their policing identities and so our data also provided evidence for Bradford and Quinton's (2014: 1039) assertion that "police officers are likely to have multiple, cross-cutting and possibly contradictory identities and beliefs". Accordingly, the interviewees made varied and nuanced intragroup (i.e., with other police officers) and intergroup (e.g., with 'the public') social comparisons, categorisations and differentiations. For example, interviewees often talked about themselves in terms of their specific role or team (e.g., 'us' response officers) and contrasted this with other policing roles and officers (e.g., 'them' as neighbourhood officers). Officers also described equally complicated understandings of, and relations to, multiple 'publics' or 'communities' (often depicted along geographical, socioeconomic and implicitly ethnic lines). This serves to highlight the potential over-simplification of using phrases and abstract social categories such as "public perceptions' and 'citizens' within our theorisation. These terms are a common feature of PJT work, and our findings suggest that they may obscure an underlying complexity in how police officers view themselves relative to those that they interact with (and vice versa).

Accordingly, the complicated and varied descriptions of 'self' and 'other' in officer talk pose some challenges to the identity-based models of procedural justice. As outlined in the introduction, both the Group Engagement Model (Tyler and Blader, 2003) and the Group Value Model (Lind and Tyler, 1988) are premised on the assumption that the police and 'the public' broadly comprise one social group (e.g., community, nation state). Bradford and Quinton (2014) expanded the logic of these models (in particular the Group Engagement Model) in order to explore police identity as a measure of an officer's belonging to their police force. This is an advance in that it recognised that the police officers may see themselves and their colleagues as a psychologically distinct social group (as can members of 'the public', see Radburn et al., 2018). However, Bradford and Quinton's 
(2014) emphasis was still on the extent to which internal and intragroup procedures (i.e., the fairness of treatment and decision making by police supervisors) indicate to police officers their standing and value within their police force. By contrast, in line with the intergroup perspective of the social identity approach, our analysis highlights that you cannot explore police identity by reference to 'the self without also considering an officer's theory of 'the other' (Charman, 2019). In so doing, we have shown that it is difficult to theorise and impose a definition of police identity in the abstract since the form and content will change depending on the specific social comparative (often intergroup) context (Turner et al., 1987, 1994).

Additionally, this study suggests that police officers cannot be simply conceptualised as fixed power-holders by virtue of their societal position (Bottoms and Tankebe, 2012). Rather our interviewees' talk suggested that power emerges and functions within interactions between 'citizens', police officers and other criminal justice agents in nuanced ways (Martin and Bradford, 2019) and we report here instances of police officer disempowerment. Given this, it is important not to conceptualise police officers as de facto power-holders since feelings of disempowerment may have implications for how officers engage and interact with 'the public'. For example, a desire to reassert police power or regain 'control' of an encounter may relate to increased use of force by officers (i.e., 'contempt of cop'; c.f., Bacon, 2017).

Moreover, the analysis demonstrates the fact that interactions are experienced by police officers in a sequential fashion and thus not as discrete, separate and bounded encounters (Waddington et al., 2015). For instance, prior officer experiences were expressed as a justification for developing a notion of those worthy or not of police time, attention and empathy (in line with Charman, 2019). In this sense, our findings mirror the observations of Worden and McLean (2017) in that officers do not go into their encounters with citizens with a psychological tabula rasa and so the extent to which officers can realistically be expected to adhere to the PJT principle of 'neutrality' in practice is questionable. This historical dimension to police-'citizen' interactions also relates to a broader point - that existing PJT research tends to focus on the impact of initial moments of contact between a police officer and a 'citizen', assuming that such an encounter is with a 'citizen' who largely obeys the law or at least starts from that normative position (Tyler, 1990). Work is therefore rarely focused on how the interaction continues (often with the involvement of multiple officers and/or criminal justice 'actors') if and when that 'citizen' who may be unwilling to comply with the law becomes a 'person in custody'. However, in contrast, our analysis underlines (from a police perspective) this complex journey and thus highlights the importance of longitudinal work in order 
to further explore the intricate and changing dynamics of power, legitimacy and identity within police-'public' encounters, particularly among those with whom the police often have regular, ongoing and often problematic relationships (Radburn and Stott, 2019).

Notwithstanding these insights, there are some important limitations of this study that need to be acknowledged. Firstly, this work represents only an initial empirical examination of Radburn and Stott (2019) and others (e.g., Bottoms and Tankebe, 2012; O’ Brien et al., 2019; Urbanska et al., 2019) recent critiques of PJT which revolve around complex theoretical questions of social identity, the nature of police-public interactions and calls for methodological and epistemological pluralism amongst other important issues. While this has been useful a more extensive and longitudinal ethnographic and/or observational research will be needed to unpack the 'teachable moments' (Tyler, Fagan and Geller, 2014) of police-'public' interactions. Secondly, and relatedly, whilst we have explored officers' talk about their interactions with 'the public', we have not observed actual police-'public' interactions in context. As Waddington (1999: 302) argues: "If we wish to explain...police behaviour on the streets, then we should look not in the remote recesses of what officers say in the canteen or privately to researchers, but in the circumstances in which they act". Thirdly, our theoretical and empirical contribution is related to the fact that we have concentrated on the police perspective of police-'citizen' encounters, whereas previous work has largely focused on what Bottoms and Tankebe (2012) referred to as the 'audience' of policing (i.e., 'the public'). Ideally, both 'the public' and police perspectives should be sought to try and gain a more complete understanding of particular dynamics and patterns of police-'citizen' interaction in situ. Again, this points towards the potential value of observational/ethnographic research.

However, taking these limitations into account, this paper has highlighted the complexity of police officers' internalised understandings of themselves, their relations to their colleagues and 'the public'. Thus, whilst acknowledging Loftus' (2010) distinction between officer talk and behaviour, and the fact that the former in isolation can never fully explain the latter (Waddington 1999), we maintain that officer talk is evidence of their "...internal categories of understanding..." and is therefore reflective of their thoughts and direct experiences (Reicher, 2000: 3). The advantage of our qualitative approach, in contrast to the large-scale quantitative survey methodology that characterises much existing PJT research, is that we were able to inductively explore officer phenomenology (c.f., Harkin, 2015). In so doing, the analysis served to challenge PJT's fairly static and limited conceptualisation of social identity processes and points to the changing dynamics of power and legitimacy within specific police-citizen encounters. In this sense, it is hoped that this 
study will act as a further demonstration of the value of moving beyond the cross-sectional survey work that predominates the existing literature.

Accordingly, this paper underlines Radburn and Stott's (2019) assertion that qualitative research is an underutilised yet necessary part of the drive to develop PJT theoretically. The analysis suggests that an adequate conceptualisation and study of police identity cannot merely focus on the 'self and intragroup processes. Instead, our work demonstrates that in order to understand police identity researchers must also explore officers' 'theory of the other' (Charman, 2019). Thus, our work points to the intergroup nature of police-'citizen' interactions within which identity and power are key dynamics. In summary, there is much to be gained both theoretically and empirically, in PJT researchers moving beyond a conceptualisation of identity as merely an emotional sense of belonging and attachment to an in-group, and instead exploring identity as a theory of internalised social (intergroup) relations.

\section{References}

Bacon M (2016) Taking Care of Business: Police Detectives, Drug Law Enforcement and Proactive Investigation. Oxford, United Kingdom: Oxford University Press.

Banton M (1964) The Policeman in the Community. London: Tavistock.

Bottoms A and Tankebe J (2012) Beyond procedural justice: a dialogic approach to legitimacy in criminal justice. The Journal of Criminal Law and Criminology 102(1): 119-170.

Bradford B (2014) Policing and social identity: procedural justice, inclusion and cooperation between police and public. Policing and Society 24(1): 22-43. DOI: 10.1080/10439463.2012.724068.

Bradford B, Murphy K and Jackson J (2014) Officers as mirrors: policing, procedural justice and the (re)production of social identity. British Journal of Criminology 54(4): 527-550. DOI: $10.1093 / \mathrm{bjc} / \mathrm{azu} 021$.

Bradford B and Quinton P (2014) Self-legitimacy, police culture and support for democratic policing in an English constabulary. British Journal of Criminology 54(6): 1023-1046. DOI: $10.1093 / \mathrm{bjc} / \mathrm{azu} 053$.

Charman S (2017) Police Socialisation, Identity and Culture: Becoming Blue. London: Palgrave Macmillan. 
Charman S (2018) From crime fighting to public protection: the shaping of police officers' sense of role, Perspectives on Policing: Paper 3.: Available from: http://www.policefoundation.org.uk/publications/perspectives-on-policing/.

Charman S (2019) Making sense of policing identities: the 'deserving' and the 'undeserving' in policing accounts of victimisation. Policing and Society: Advanced Online Access, first published April 3rd, 2019. DOI: 10.1080/10439463.2019.1601721.

Clarke J, Newman J, Smith N, Vidler E and Westmarland, L (2007) Creating Citizen-Consumers: Changing Publics and Changing Public Services. London: SAGE.

Glaser BG and Strauss AL (2017) The Discovery of Grounded Theory: Strategies for Qualitative Research. New York: Routledge.

Harkin D (2015) Police legitimacy, ideology and qualitative methods: a critique of procedural justice theory. Criminology and Criminal Justice 15(5): 594-612. DOI: 10.1177/1748895815580397.

Henwood K and Pidgeon N (2003) Grounded theory in psychological research. In: Camic PM, Rhodes JE, and Yardley L (eds) Qualitative Research in Psychology: Expanding Perspectives in Methodology and Design. Washington, DC: American Psychological Association, pp. 131-155.

Herbert S (2006) Tangled up in blue: conflicting paths to police legitimacy. Theoretical Criminology 10(4): 481-504. DOI: $10.1177 / 1362480606068875$.

Jackson J, Bradford B, Hough M, et al. (2012) Why do people comply with the law?: Legitimacy and the influence of legal institutions. British Journal of Criminology 52(6): 1051-1071. DOI: $10.1093 / \mathrm{bjc} / \mathrm{azs} 032$.

Jackson J and Posch KP (2020) New directions of research in fairness and legal authority: a focus on causal mechanisms. In: Lind EA (ed.) Social Psychology and Justice. Abingdon, UK: Routledge.

Lind EA and Tyler TR (1988) The Social Psychology of Procedural Justice. New York, NY: Plenum.

Loftus B (2010) Police occupational culture: classic themes, altered times. Policing and Society 20(1): 1-20. DOI: 10.1080/10439460903281547.

MacQueen S and Bradford B (2015) Enhancing public trust and police legitimacy during road traffic encounters: results from a randomised controlled trial in Scotland. Journal of Experimental Criminology 11(3): 419-443. DOI: 10.1007/s11292-015-9240-0. 
Martin R and Bradford B (2019) The anatomy of police legitimacy: Dialogue, power and procedural justice. Theoretical Criminology: Advanced Online Access, first published December 19th, 2019. DOI:10.1177/1362480619890605

Miller SL (1999) Gender and Community Policing: Walking the Talk. Boston, MA: North-Eastern University Press.

O’Brien TC, Tyler TR and Meares TL (2019) Building popular legitimacy with reconciliatory gestures and participation: A community level model of authority. Regulation \& Governance: Advanced Online Access, first published July 3rd, 2019. DOI: 10.1111/rego.12264.

Radburn M and Stott C (2019) The social psychological processes of 'procedural justice': concepts, critiques and opportunities. Criminology \& Criminal Justice 19(4): 421-438. DOI: $10.1177 / 1748895818780200$.

Radburn M, Stott C, Bradford B, et al. (2018) When is policing fair? Groups, identity and judgements of the procedural justice of coercive crowd policing. Policing and Society 28(6): 647-664. DOI: $10.1080 / 10439463.2016 .1234470$.

Reicher S (2000) Against methodolatry: some comments on Elliott, Fischer, and Rennie. British Journal of Clinical Psychology 39(1): 1-6. DOI: 10.1348/014466500163031.

Reiner R (2010) The Politics of the Police. 4th ed. Oxford, UK: Oxford University Press.

Sklansky D (2007) Seeing blue: police reform, occupational culture and cognitive burn-in. In: O’Neill M, Marks M and Singh A-M (eds) Police Occupational Culture: New Debates and Directions. Oxford: Elsevier, pp. 19-47.

Skolnick JH (1966) Justice without Trial: Law Enforcement in Democratic Society. New York: Macmillan.

Smith B and McGannon KR (2018) Developing rigor in qualitative research: problems and opportunities within sport and exercise psychology. International Review of Sport and Exercise Psychology 11(1): 101-121. DOI: 10.1080/1750984X.2017.1317357.

Sunshine J and Tyler TR (2003a) The role of procedural justice and legitimacy in shaping public support for policing. Law and Society Review 37(3): 513-548. DOI: 10.1111/1540-5893.3703002. 
Sunshine J and Tyler TR (2003b) Moral solidarity, identification with the community, and the importance of procedural justice: the police as prototypical representatives of a group's moral values. Social Psychology Quarterly 66(2): 153-165. DOI: 10.2307/1519845.

Tajfel H (1981) Human Groups and Social Categories: Studies in Social Psychology. New York: Cambridge University Press.

Tajfel H and Turner JC (1979) An integrative theory of intergroup conflict. In: Austin WG and Worchel S (eds) The Social Psychology of Intergroup Relations. Monterey, CA: Brooks Cole., pp. 33-47.

Turner JC, Hogg MA, Oakes PJ, et al. (1987) Rediscovering the Social Group: A Self-Categorization Theory. Cambridge, MA, US: Basil Blackwell.

Turner JC, Oakes PJ, Haslam SA, et al. (1994) Self and collective: cognition and social context. Personality and Social Psychology Bulletin 20(5): 454-463. DOI: 10.1177/0146167294205002.

Tyler TR (1990) Why People Obey the Law. Princeton, N.J: Princeton University Press.

Tyler TR and Blader SL (2003) The group engagement model: procedural justice, social identity, and cooperative behavior. Personality and Social Psychology Review 7(4): 349-361. DOI: 10.1207/S15327957PSPR0704_07.

Tyler TR, Fagan J and Geller A (2014) Street stops and police legitimacy: teachable moments in young urban men's legal socialization: street stops and police legitimacy. Journal of Empirical Legal Studies 11(4): 751-785. DOI: 10.1111/jels.12055.

Urbanska K, Pehrson S, Platow MJ, et al. (2019) Authority fairness as contingent on intergroup attitudes: review and expansion of relational models of procedural justice. PsyArXiv Preprints: Advanced Online Access, first published June 11th, 2019. DOI: 10.31234/osf.io/j9ndy.

Waddington P (1994) Liberty and Order: Public Order Policing in a Capital City. London: UCL Press.

Waddington P (1999) Police (canteen) sub-culture. An appreciation. British Journal of Criminology 39(2): 287-309. DOI: 10.1093/bjc/39.2.287.

Waddington P, Williams K, Wright M, et al. (2015) Dissension in public evaluations of the police. Policing and Society 25(2): 212-235. DOI: 10.1080/10439463.2013.833799.

Westley WA (1970) Violence and the Police: A Sociological Study of Law, Custom, and Morality. Cambridge, Massachusetts: MIT Press. 
Worden RE and McLean SJ (2017) Mirage of Police Reform: Procedural Justice and Police Legitimacy.

Oakland, California: University of California Press.

\section{Acknowledgements}

We would like to thank all of our interviewees for their time and integral contribution to this work. We would also like to thank Ben Bradford and Jon Jackson for reviewing an earlier version of this manuscript.

\section{Declaration of Conflicting Interests}

The author(s) declared no potential conflicts of interest with respect to the research, authorship, and/or publication of this article.

\section{Funding}

The Economic Social Research Council (grant number: ES/R011397/1) supported this work. See: https://gtr.ukri.org/projects?ref=ES\%2FR011397\%2F1 for further details.

\section{Author biographies}

Matthew Radburn is currently a Post-Doctoral Research Fellow at Keele University working on a range of policing related projects as part of the academic team within the Keele Policing Academic Collaboration (KPAC). Email: m.radburn@keele.ac.uk

Leanne Savigar-Shaw is a Lecturer in Policing at Staffordshire University. She is currently involved in ethnographic research concerning police-public interaction, procedural justice and fairness within policing. Her research interests also include road safety, driver education, and in particular, mobile phone use by drivers. Email: leanne.savigar-shaw@staffs.ac.uk

Clifford Stott is currently a Professor of Social Psychology at Keele University and founder and Director of the Keele Policing Academic Collaboration (KPAC). His interdisciplinary research expertise focuses on issues of social identity, procedural justice, human rights and group level dynamics as these relate to crowds, riots, hooliganism and policing. Email: c.stott@keele.ac.uk

Deborah Tallent currently works at Keele University as the Centre Manager of the Keele Policing Academic Collaboration. Email: d.j.tallent@keele.ac.uk 
Arabella Kyprianides is currently working at University College London, within the Institute for Global City Policing (IGCP), as the Post-Doctoral Research Fellow primarily leading UCL's ethnographic strand of the ESRC funded project "From coercion to consent: social identity, legitimacy, and a process model of police procedural justice (CONSIL)”. Email: a.kyprianides@ucl.ac.uk

\section{Author Notes:}

Matthew Radburn, School of Psychology, Keele University; Leanne Savigar-Shaw, School of Law, Policing \& Forensic Science, Staffordshire University; Clifford Stott, School of Psychology, Keele University; Deborah Tallent, School of Psychology, Keele University; Arabella Kyprianides, Department of Security and Crime Science, University College London.

Correspondence concerning this article should be addressed to Matthew Radburn, School of Psychology, Dorothy Hodgkin Building, Keele University, Keele, Staffordshire, ST5 5BG, UK. E-mail: m.radburn@,keele.ac.uk 